\title{
Dominant Role of $\beta \gamma$ Subunits of G-Proteins in Oxytocin-Evoked Burst Firing
}

\author{
Yu-Feng Wang and Glenn I. Hatton \\ Department of Cell Biology and Neuroscience, University of California, Riverside, Riverside, California 92521
}

Pulsatile neuropeptide secretion is associated with burst firing patterns; however, intracellular signaling cascades leading to bursts remain unclear. We explored mechanisms underlying burst firing in oxytocin (OT) neurons in the supraoptic nucleus in brain slices from lactating rats. Application of $10 \mathrm{pM}$ OT for 30 min or progressively rising OT concentrations from 1 to 100 pм induced burst firing in OT neurons in patch-clamp recordings. Burst generation was blocked by OT antagonist and ionotropic glutamate receptor blockers or tetanus toxin. Blocking G-protein activation with suramin or intracellular GDP- $\beta$-S, but not intracellularly administered antibody against the OT-receptor (OTR) C terminus, blocked bursts. Moreover, pretreatment of slices with pertussis toxin, an inhibitor of $\mathrm{G}_{\mathrm{i} / \mathrm{o}^{-}}$ proteins, did not block OT-evoked bursts, suggesting that $\mathrm{G}_{\mathrm{i}} / \mathrm{G}_{\mathrm{o}}$ activation is unnecessary for burst generation. Thus, we further examined $\mathrm{G} \alpha_{\mathrm{q} / 11}$-associated signaling pathways in OT-evoked bursts. Inhibition of phospholipase C or RhoA/Rho kinase did not block bursts. Activation of $\mathrm{G} \beta \gamma$ subunits using myristoylated $\mathrm{G} \beta \gamma$-binding peptide (mSIRK) caused bursts, whereas intracellularly loaded antibody against G $\beta$ subunit blocked OT-evoked bursts. Blocking Src family kinase, but not phosphatidylinositol 3-kinase, occluded OT-evoked bursts. Similar to the effects of OT on EPSCs, mSIRK inhibited tonic EPSCs and elicited EPSC clustering. Finally, suckling caused dissociation of OTRs and $\mathrm{G} \beta$ subunits from $\mathrm{G} \alpha_{\mathrm{q} / 11}$ subunits shown by coimmunoprecipitation and immunocytochemistry, supporting crucial roles for OTRs and $\mathrm{G} \beta \gamma$ subunits in the milk-ejection reflex. We conclude that $\mathrm{G} \beta \gamma$ subunits play a dominant role in burst firing evoked by applied OT or by suckling.

Key words: coimmunoprecipitation; $\mathrm{G} \alpha_{\mathrm{q} / 11}$ subunit; milk-ejection reflex; oxytocin receptor; signal transduction; Src family kinase

\section{Introduction}

Burst firing patterns occur during neural development, rhythmic activities of local neural circuits, and neurosecretion. During development, the firing patterns of young hypothalamic neurons change from pro-tonic to proburst patterns (Wang et al., 2001). Rhythmic bursting activities in mature neurons are seen in hippocampal epileptiform discharges (Su et al., 2001), brainstem respiratory pattern generators (Dunin-Barkowski et al., 2003), and spinal neural networks (Darbon et al., 2003). Exemplary burst firing patterns in neurosecretion are the pulse generators of gonadotropin-releasing hormone neurons (Suter et al., 2000) and burst discharges of supraoptic nucleus (SON), oxytocin (OT), and vasopressin (VP) neurons [for review, see Hatton (1990) and Crowley and Armstrong (1992)]. Despite the diversity of their explicit features, bursts share common electrophysiological machinery. However, intracellular signaling pathways leading to burst generation are not yet well understood.

Bursts of OT neurons distinguish themselves from others by being highly transient during prolonged basal firing (Wakerley

Received Aug. 17, 2006; revised Jan. 17, 2007; accepted Jan. 18, 2007.

This work was supported by National Institutes of Health Grant NS009140. We thank Dr. Todd A. Ponzio for helpful suggestions on a previous draft of this manuscript and the Center for Plant Cell Biology at the University of California, Riverside, for use of the Leica confocal microscope.

Correspondence should be addressed to Yu-Feng Wang, Department of Cell Biology and Neuroscience, University of California, Riverside, Riverside, CA 92521. E-mail: yufengw@ucr.edu.

D01:10.1523/JNEUROSCI.5346-06.2007

Copyright $\odot 2007$ Society for Neuroscience $\quad$ 0270-6474/07/271902-11\$15.00/0 and Lincoln, 1973; Wang and Hatton, 2004). In burst generation in vivo, somatodendritically secreted OT plays a crucial role (Freund-Mercier and Richard, 1984; Moos et al., 1989). Our preliminary work using patch-clamp recording, published in abstract form (Hatton and Wang, 2005), has confirmed the efficacy of OT in evoking bursts. The major signaling pathway via OT receptors (OTRs) was believed to be the $\mathrm{G}_{\mathrm{q} / 11}$-type $\mathrm{G}$-proteincoupled receptor (GPCR) and its downstream effectors (for review, see Gimpl and Fahrenholz, 2001). However, the potential role of $\mathrm{G} \alpha_{\mathrm{q} / 11}$-associated $\mathrm{G} \beta \gamma$ subunits in neurons has not been fully explored. Theoretically, activation of GPCRs in OT neurons may also release $\mathrm{G} \beta \gamma$ subunits that have been implicated in OT peripheral actions (Hoare et al., 1999; Zhong et al., 2003). Contrary to classical views on GPCR signaling, the G $\beta \gamma$ subunits are the major mediators of OT-evoked activation of extracellular signal-regulated protein kinases 1 and 2 (ERK1/2) in myometrium (Zhong et al., 2003). In neurons, G-protein $\beta \gamma$ subunits were also implicated in modulating electrical activities. In acutely dissociated hippocampal neurons, $\mathrm{Ba}^{2+}$ current via $\mathrm{N}$-type voltage-dependent $\mathrm{Ca}^{2+}$ channels was inhibited by activation of $\mathrm{G} \beta \gamma$ subunits (Blumenstein et al., 2004). Amplitude of the glycine-activated $\mathrm{Cl}^{-}$current was enhanced after application of purified G-protein $\beta \gamma$ subunits or after activation of a GPCR in the mammalian brainstem and spinal cord (Yevenes et al., 2003). Together, this evidence suggests that signaling pathways of $G \beta \gamma$ subunits may also be involved in burst generation.

In our previous work, we found that OT in concentrations 
A

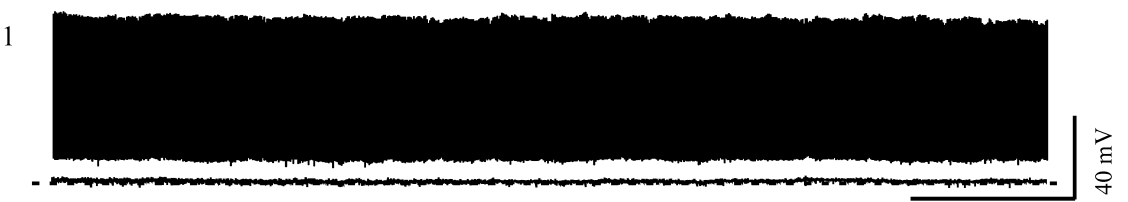

$-51 \mathrm{mV}$

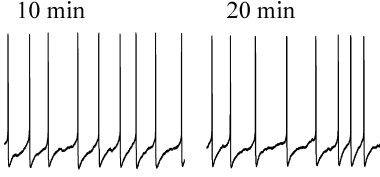

$30 \mathrm{~min}$

$40 \mathrm{~min}$

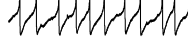

B
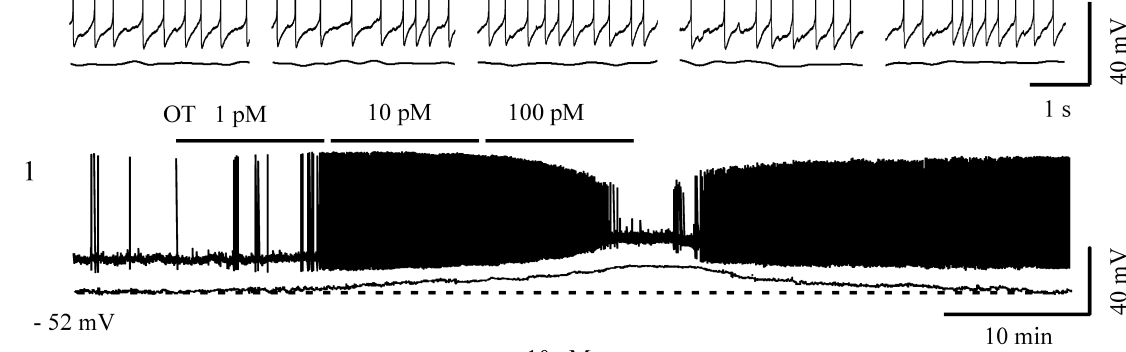

2

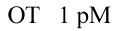

$10 \mathrm{pM}$

$100 \mathrm{pM}$
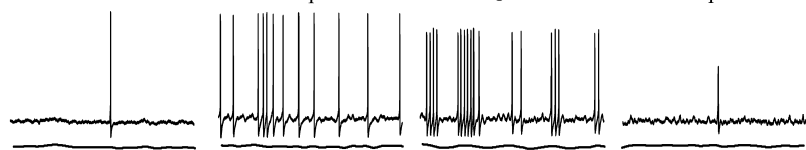

OT 1 pM 10 pM 100 pM

C
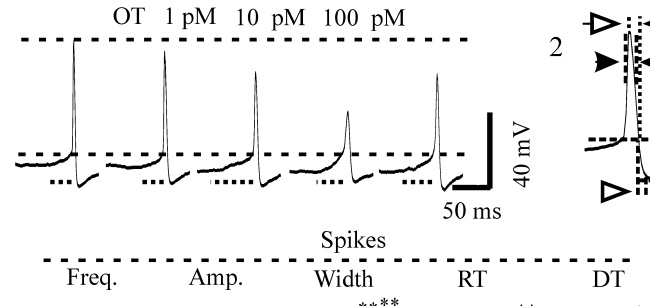

Width
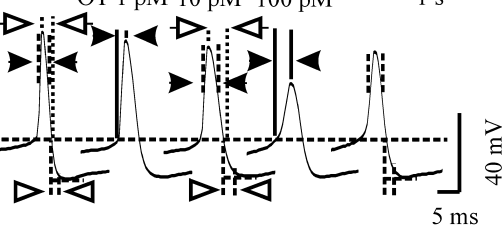

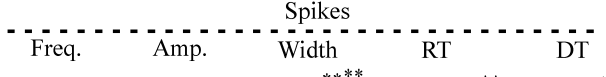
STD

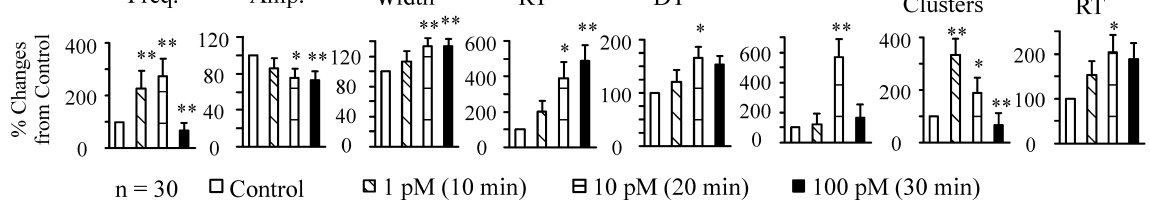

Figure 1. Effects of OT on the membrane electrical features in OT neurons. $\boldsymbol{A}$, Firing activity in an OT neuron without special stimulation over $60 \mathrm{~min}$ in whole recording $(\boldsymbol{A} \mathbf{1})$ and its expanded episodes (A2) from different time points in patch-clamp recordings. The bottom traces under the recordings in $\boldsymbol{A}$ and $\boldsymbol{B}$ show $E_{\mathrm{m}}$ after Gaussian low-pass filtering ( $-3 \mathrm{~dB}$ cutoff at $0.4 \mathrm{~Hz}$ ) to remove action potentials. The dashed lines indicate the level of the pretreatment $E_{\mathrm{m}}$ (bottom left). $\boldsymbol{B}, \mathrm{An}$ example of the effects of OT on general membrane electrical features. B1, OT neuronal activity during progressively increasing concentrations of OT in whole recording (top) and its expanded episodes (B2) from different time points. $\boldsymbol{C}$, Examples showing detailed changes in the $E_{\mathrm{m}}$ and spikes. C1, The long dashed lines correspond to spike threshold (bottom) and the peak of initial spike (top); the distance between the two lines shows spike amplitudes. Dotted lines below selected traces indicate the time courses of subthreshold $E_{\mathrm{m}}$ depolarization (STD) leading to spike generation. $\mathbf{2}$, Individual examples showing spike details. The long dashed line corresponds to spike threshold. Distances between the dashed vertical lines above and below the long horizontal line indicate the $50 \%$ amplitude width of spikes (between filled arrows) and $50 \%$ time of the rising phase (between open arrowheads) of the spike AHP, respectively. The distance between the solid vertical lines before the peak of spike (filled arrowheads) and between the dotted lines after the peak of spike (open arrows) show the rising and decay times of spikes, respectively. D, Summary graphs showing the effects of $0 \mathrm{~T}(n=30)$ on the frequency (Freq.), amplitude (Amp.), $50 \%$ amplitude width, and rising time (RT) and decay time (DT) constants of the spikes; STD; incidence of spike clusters; and the RT of the AHPs. The point measurements in $\boldsymbol{D}$ were taken over 5 min near the end of each section. ${ }^{*} p<0.05$ and ${ }^{* *} p<0.01$ compared with control by paired $t$ test after evaluation with ANOVA

much lower than physiological range initially excites and subsequently inhibits OT neuronal activity (Wang et al., 2006). In the present work, we further explored burst firing and its underlying mechanisms in OT neurons evoked by OT at concentrations close to or within the physiological range in acute brain slices from adult lactating rats. Our results indicate that $\mathrm{G}_{\mathrm{q}_{111^{-}}}$ associated $\mathrm{G} \beta \gamma$ subunits play a dominant role in burst firing of OT neurons at presynaptic and postsynaptic sites. Finally, we
$10 \mathrm{~min}$
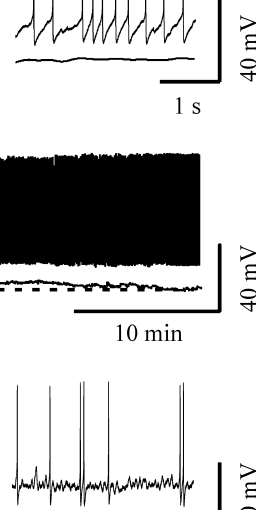

Spike AHP

confirmed that suckling in intact animals mobilizes OTRs and $\mathrm{G} \alpha_{\mathrm{q} / 11}$-associated $\mathrm{G} \beta \gamma$ subunits, which very likely function in the generation of milk-ejection bursts in lactating animals.

\section{Materials and Methods}

All procedures in the animal experiments follow the guidelines on the use and care of laboratory animals set by the National Institutes of Health and approved by the Institutional Animal Care and Use Committee of the University of California, Riverside.

Electrophysiology. Sprague Dawley (Holtzman strain) female rats lactating for $8-13 \mathrm{~d}$ were used for the experiments. Rats were decapitated with a guillotine. Brains were quickly removed and put in an oxygenated, ice-cold artificial CSF (aCSF) for $1 \mathrm{~min}$. The aCSF contained the following (in mM): $126 \mathrm{NaCl}, 3 \mathrm{KCl}$ $1.3 \mathrm{MgSO}_{4}, 2.4 \mathrm{CaCl}_{2}, 1.3 \mathrm{NaH}_{2} \mathrm{PO}_{4}, 26$ $\mathrm{NaHCO}_{3}, 10$ glucose, 0.2 ascorbic acid, $\mathrm{pH} 7.4$ adjusted with 23 -( $N$-morpholino) propanesulfonic acid and maintained with $95 \% \mathrm{O}_{2} / 5 \%$ $\mathrm{CO}_{2}$ gas mixture after filtering. The osmolality was adjusted to $300 \mathrm{mOsm} / \mathrm{kg}$. Hypothalami were dissected from the brain and cut coronally on a vibratome into $300-\mu$ m-thick slices. After preincubation at room temperature $\left(21-23^{\circ} \mathrm{C}\right)$ for at least $1 \mathrm{~h}$, the slices were used for electrical recordings at $35^{\circ} \mathrm{C}$. Whole-cell patch-clamp methods were used to record membrane potential $\left(E_{\mathrm{m}}\right)$, action potentials, and EPSCs. Patch-pipette filling solution contained the following (in $\mathrm{mm}$ ): $145 \mathrm{~K}$-gluconate, $10 \mathrm{KCl}, 1$ $\mathrm{MgCl}_{2}, 10$ HEPES, 1 EGTA, $0.01 \mathrm{CaCl}_{2}, 2 \mathrm{Mg}$ ATP, $0.5 \mathrm{Na}_{2}$-GTP, pH 7.3 , adjusted with $\mathrm{KOH}$. To locate the recorded cells for later immunocytochemical identification, $0.05 \%$ Lucifer yellow $\left(\mathrm{K}^{+}\right.$salt $)$was added to the pipette solution. Patch electrodes were visually guided onto SON cells through an upright microscope (DM LFSA; Leica Microsystems, Heidelberg, Germany) equipped with water-immersion objectives and filters for fluorescence microscopy. Whole-cell recordings were obtained from the somata of SON magnocellular neurons during perifusion of aCSF via a gravityfeed perifusion system at a rate of 1.2-1.5 ml/ min. An Axoclamp 2B amplifier was used for collecting electrical signals that were filtered and sampled at $5 \mathrm{kHz}$ by Clampex 9 software through a 1320 analog/digital converter (Molecular Devices, Union City, CA). Data were stored in a personal computer for off-line analysis.

Chemicals, drugs, and antibodies used. Goat polyclonal antibody against OT-neurophysin (OT-NP), rabbit polyclonal antibody against VP-neurophysin (VP-NP), goat polyclonal antibodies against OTRs, and rabbit polyclonal antibodies against $\mathrm{G} \alpha_{\mathrm{q} / 11}$ or $\mathrm{G} \beta$ subunit of G-proteins were from Santa Cruz Biotechnology (Santa Cruz, CA). Alexa Fluor 647- or 555-labeled donkey anti-goat antibody and Alexa Fluor 488- or 647-labeled donkey anti-rabbit antibody were from Invitrogen (Eugene, OR). Protein A/G agarose was from Millipore (Bedford, MA). Myristoylated G-protein $\beta \gamma$-binding peptide [myristoyl-SIRKALNILGYPDYD (mSIRK)] was from EMD Biosciences (La Jolla, CA). All reagents for Western blotting were from GE Health- 
care (Piscataway, NJ) except for the horseradish peroxidase-conjugated goat IgG antibody, which was from Bethyl Laboratories (Montgomery, TX). All other drugs were from Sigma (St. Louis, MO).

Immunocytochemistry. The methods for chemically identifying recorded neurons were modified from those described previously (Smithson and Hatton, 1990). Briefly, after recording with electrodes containing Lucifer yellow in the pipette solution, slices were fixed overnight with $4 \%$ paraformaldehyde at $4^{\circ} \mathrm{C}$ and treated with $0.3 \%$ Triton X-100 for $30 \mathrm{~min}$. After incubation with goat polyclonal OT-NP antibody (dilution, 1:250) and rabbit polyclonal VP-NP antibody (dilution, 1:250) for $4 \mathrm{~h}$ at room temperature, appropriate secondary antibodies (1:1000) were applied for $1.5 \mathrm{~h}$ to label OT neurons and VP neurons. For identification of $\mathrm{G} \alpha_{\mathrm{q} / 11}$ subunits or $\mathrm{G} \beta$ subunits, the same methods as described previously (Wang and Hatton, 2006) were applied, except for the concentration of antibodies used (1:250 for $4 \mathrm{~h}$ at room temperature) or as otherwise noted in Results.

Western blots and coimmunoprecipitation. Lactating rats were separated from all pups for $4 \mathrm{~h}$, and then $\sim 10 \mathrm{~min}$ of suckling was applied (suckling) or not (control). Animals were decapitated, and the SON was dissected out, put in the cold lysis buffer, and run for Western blots as described in our previous work (Wang and Hatton, 2006). For coimmunoprecipitation, total lysates were precleared with protein A agarose to reduce nonspecific binding of proteins to the agarose beads when used later in the assay. Slice lysates $(500-1500 \mu \mathrm{g}$ per $500 \mu \mathrm{l})$ were added to $1.5 \mu \mathrm{g}$ of immunoprecipitating antibody $\left(\mathrm{G} \alpha_{\mathrm{q} / 11}\right.$ or $\left.\mathrm{G} \beta\right)$ to form an immunocomplex. After overnight incubation at $4^{\circ} \mathrm{C}$ on an orbital shaker, the immunocomplexes were captured by adding $50 \mu \mathrm{l}$ of protein A agarose bead slurry and gently rocking on an orbital shaker for $2 \mathrm{~h}$ at $4^{\circ} \mathrm{C}$. The agarose beads were collected by a pulse centrifugation (i.e., $10 \mathrm{~s}$ in the microcentrifuge at 13,000 rpm). After discarding the supernatant and washing the beads three times with $800 \mu$ lof ice-cold buffer, the agarose beads were resuspended in $50 \mu$ l of $2 \times$ sample buffer (Bio-Rad, Hercules, CA) and mixed gently. Beads were boiled for $10 \mathrm{~min}$ (as in Western blot) to dissociate the immunocomplex from the beads. The beads were collected by centrifugation, and the supernatant was run on $10 \%$ SDS-polyacrylamide gel. Protein was transferred onto a nitrocellulose membrane at $4^{\circ} \mathrm{C}$. The membrane was pretreated with $5 \%$ milk solids for $1 \mathrm{~h}$ at room temperature and then incubated with antibodies against $\mathrm{G} \alpha_{\mathrm{q} / 11}$ (rabbit, 1:300), OTRs (goat, 1:300), or $\mathrm{G} \beta$ (rabbit, 1:300) for $4 \mathrm{~h}$ at room temperature with necessary stripping of membranes. Protein bands were visualized using horseradish peroxidase-conjugated secondary antibodies and an enhanced chemiluminescence system (GE Healthcare). All samples were run at least in triplicate.

Data collection and analysis. Data were collected after firing rate and $E_{\mathrm{m}}$ level became stable in whole-cell configuration, which usually took 10-20 min. Identification of OT and VP neurons were basically the same as our previous work (Wang and Hatton, 2006). In vitro bursts of OT neurons had to present all electrophysiological features of the milkejection burst (Wakerley and Lincoln, 1973) with or without (in the presence of blocking agents only) spike features of bursts evoked by the $\alpha_{1}$ adrenoceptor agonist phenylephrine (Wang and Hatton, 2004). Mea-
2. Burst firing
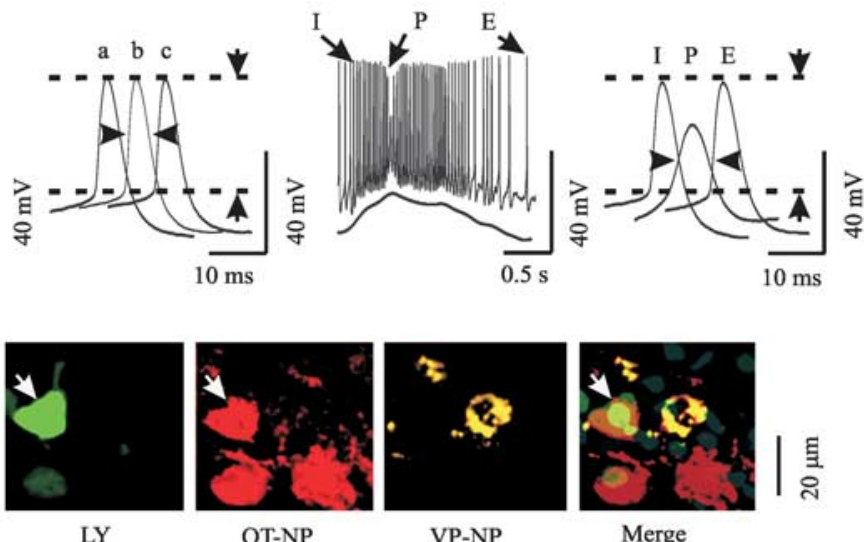

VP-NP

Merge

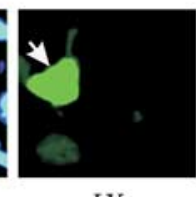

OT-NP

AHP Amp. Width RT DT
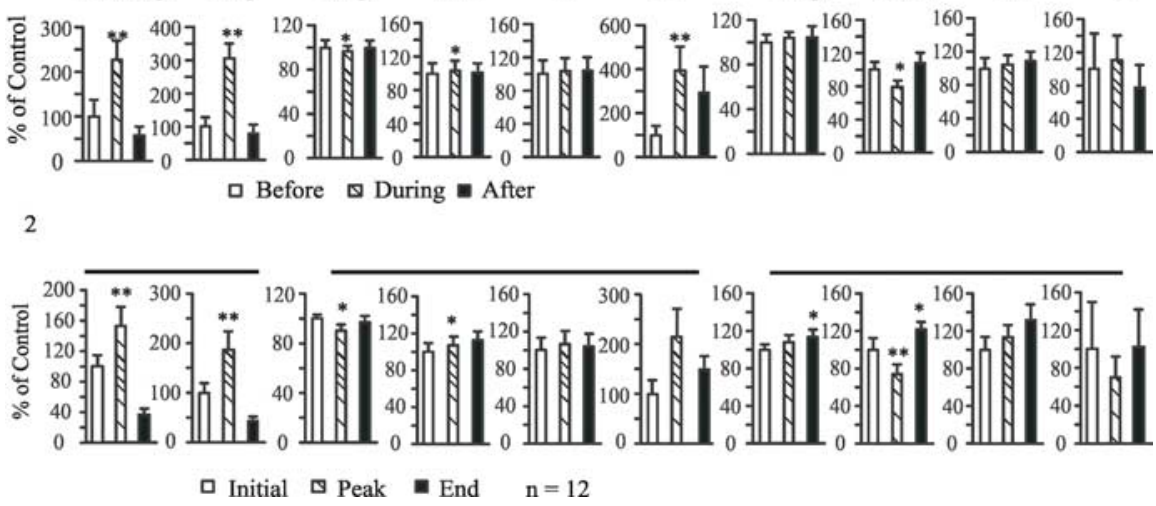

Figure 2. Effects of $0 T$ on the burst firing. $A$, An example of bursts in patch-clamp recordings and basic membrane electrical features of bursts in response to $0 \mathrm{~T}$ stimulation ( $10 \mathrm{pm} 0 \mathrm{~T}$ for $30 \mathrm{~min}$ ). $0 \mathrm{~T}$ neurons changed firing pattern from tonic during control

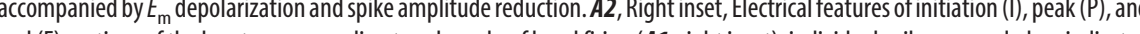
ing is positive for OT NP (in rict wh wing the effects of $0 \mathrm{~T}$ on the spike details. Inst-Freq., Instantaneous firing rate. Other abbreviations are the same as in Figure 1. ${ }^{*} p<0.05$ and ${ }^{* *} p<0.01$ compared with control (100\%). C1, Data at $0-4$ s before, during, and $0-4$ s after the bursts. C2, Three spikes at the initial, peak, and end portions of a burst.

sured liquid junction potentials of -8 to $-11 \mathrm{mV}$ (potential of pipette solution with respect to the bath) were uncorrected in Results. In evaluation of the immunostaining, criteria similar to those used in our previous work (Wang and Hatton, 2006) were used, except that quantification of each channel was performed using Leica confocal software (version 2.5; Leica Microsystems). ANOVA, paired $t$ test, or Wilcoxon rank test and $\chi^{2}$ test were used for statistical analyses where available as instructed by SigmaStat program (SPSS, Chicago, IL), and $p<0.05$ was considered significant. All measures were expressed as mean \pm SEM, except as otherwise indicated in Results.

\section{Results}

OT neurons should fire continuously and show sustained outward rectification (Stern and Armstrong, 1997), but they do not usually fire phasically or present plateau potentials. Exemplary neurons in each group, as well as neurons that could not be classified by electrophysiological criteria, were further identified subsequently by immunocytochemistry. Firing activities were observed in 340 putative OT neurons in the SON, and 75 of them were identified immunocytochemically as being OTergic. Data 
A
Control

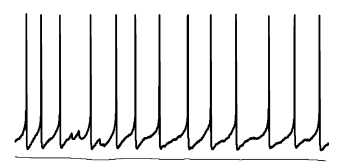

$\mathrm{CNQX}+\mathrm{AVP}$

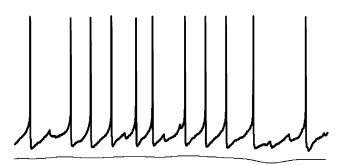

Bic.

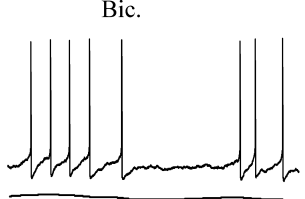

OT
$\mathrm{C}$
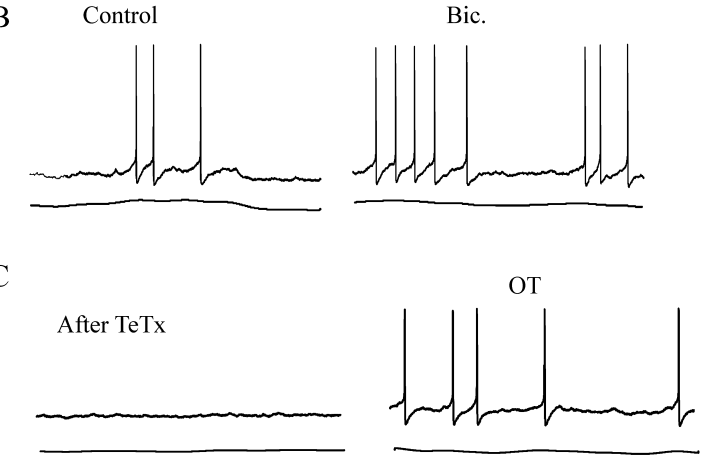

$\mathrm{CNQX}+\mathrm{AVP}+\mathrm{OT}$

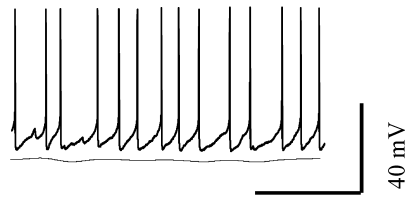

$1 \mathrm{~s}$

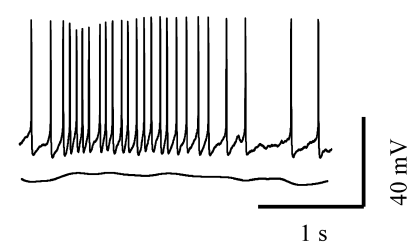

$1 \mathrm{~s}$

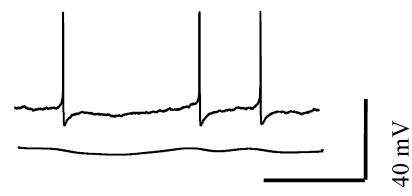

$1 \mathrm{~s}$
D

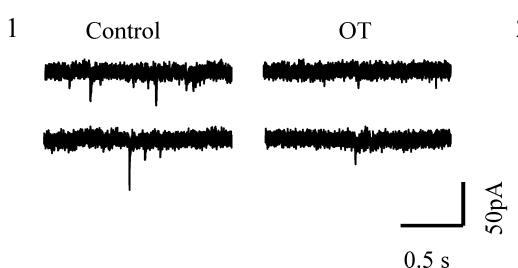

2

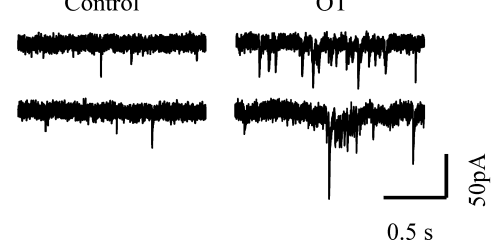

Figure 3. Synaptic transmission and OT-evoked bursts. $\boldsymbol{A}$, Effects of OT on firing activity during blockade of ionotropic glutamatergic transmission. In the presence of $10 \mu \mathrm{m}$ CNQX and $100 \mu \mathrm{m} \mathrm{APV,} \mathrm{OT} \mathrm{stimulation} \mathrm{failed} \mathrm{to} \mathrm{evoke} \mathrm{bursts.} \boldsymbol{B}$, Effects of blocking ionotropic GABAergic receptors with bicuculline (Bic.; $20 \mu \mathrm{m}$ ) on OT-evoked burst. $\mathbf{C}$, Effect of OT on the firing activity of an OT neuron after pretreatment with tetanus toxin (TeTx; $10 \mathrm{~nm}$ for $1.5 \mathrm{~h}$ ). $\boldsymbol{D}$, Effects of $0 \mathrm{~T}$ on different components of EPSCs at a holding potential of $-70 \mathrm{mV}$. D1, 0T suppressed tonic EPSCs. D2, 0T elicited EPSC clustering.

from several studies now indicate that quality recordings from SON neurons in our slices can be acquired for at least $24 \mathrm{~h}$ after slices are prepared.

\section{Effects of OT on basal firing and bursts in OT neurons}

Previous work has shown that OT in high concentration $(0.1 \mu \mathrm{M})$ accelerated preexisting bursts in organotypic cultures of newborn-rat hypothalamic slices (Jourdain et al., 1998). However, not only does extensive structural reorganization lead to new synaptic connections in neonatal slice cultures, but any depolarizing stimulus may trigger burst firing from neurons from embryos or young animals (e.g., GABA-evoked bursts in lateral hypothalamic neurons) (Wang et al., 2001). In intact animals, OT facilitates but does not evoke bursts. Spontaneous burst firing is rarely observed, which vastly differs from the frequent spontaneous bursts in organotypic cultures. Thus, the specificity of OT actions in organotypic cultures is in doubt. We recently showed that progressive increases from extremely low (0.1-10 fM) to high (0.1-10 nM) OT concentrations results first in enhanced firing activity and then in subsequent spike-frequency reduction in OT neurons (Wang et al., 2006). However, a role for OT in the generation of bursts was not clear. Therefore, we studied the effects of 1-100 pM OT [concentrations close to physiological range (Bealer and Crowley, 1999)] on OT neuronal activity, particularly on burst probability.

OT was applied in either a single concentration (10 pM for $30-45 \min ; n=20$ ) or progressively increasing concentrations (1, 10, and $100 \mathrm{pM}$, each for $10 \mathrm{~min} ; n=10)$. Because both protocols yielded the same effects on the basal firing rate and burst incidence, their effects were presented together. OT evoked an initial excitation and subsequent inhibition of the firing activity in most of the OT neurons tested (23 of 30). The peak firing rate, which was $\sim 300 \%$ of the control, appeared at $17.8 \pm 2.3 \mathrm{~min}$. After the peak firing rate, the excitability in OT neurons declined gradually, giving way to spike-frequency reduction. The dual effects of OT on firing rates were also observed in changes in the number of preburst firing patterns and the duration of subthreshold membrane potential depolarizations. These reached peak levels during the 10-20 min after OT application and then returned to basal level before washout of OT. Preburst firing patterns are spike clusters that possess a spikefrequency distribution similar to that of a burst but with a smaller number $(<10$ spikes), shorter duration (usually $<1 \mathrm{~s}$ ), and absence of postburst inhibition (Wang and Hatton, 2005). OT also caused depolarization of $E_{\mathrm{m}}$ (from $-55.1 \pm 2.4$ $\mathrm{mV}$ before OT to $-47.3 \pm 2.6 \mathrm{mV}$ at 30 min of OT; $n=30 ; p<0.01$ ), reduction in spike amplitude, increases in spike duration and rise and decay times, elevation of spike threshold, and an increase in the rise time of spike afterhyperpolarization (AHP). These effects were both time and dose dependent, obviously different from those on firing rates. As a whole, these effects are similar to but stronger than those seen in the very lowest ( $1 \mathrm{fM}$ ) to highest (10 nM) concentrations of OT (Wang et al., 2006). Exemplary recordings and summaries of the effects of OT are shown in Figure 1.

Accompanying changes in firing rate, firing patterns of OT neurons also changed in response to OT stimulation, tending toward more spike clusters and even bursts. A burst was defined as a sudden increase in firing rate, accompanied by transient depolarization of $E_{\mathrm{m}}$, reduction in spike amplitude, and increase in spike duration as the peak rate of firing was reached. This is followed by an exponential decay in firing rate after the peak rate, ending with a silent period. Application of OT elicited 12 bursts from $8(26.7 \%)$ of the 30 OT neurons (Fig. $2 \mathrm{~A})$. Most of these bursts ( 10 of 12) occurred 9-22 min after OT application. A brief depolarization of $E_{\mathrm{m}}$ (peak level, $5.0 \pm 0.5 \mathrm{mV}$ ) accompanied burst onset, with repolarization occurring after the appearance of the peak firing rate. Spikes during a burst were characterized by an increase in duration (measured at 50\% amplitude) and a decrease in amplitude. Meanwhile, the durations of AHPs were also reduced significantly. Different electrical characteristics could be identified at different portions of a burst. During peak firing rate, the amplitudes of spikes occurring atop a mostly depolarized $E_{\mathrm{m}}$ were reduced significantly. Furthermore, associated with burst peaks were (1) an increase in spike duration, (2) prolongation of spike decay phase, (3) accelerated recovery of the decay phase of AHPs, and (4) reduction in AHP duration. Near the end of bursts, amplitudes of spikes and AHPs tended to increase, firing rate returned to preburst levels, and AHP rising phase increased, 
features that are the same as those evoked by phenylephrine in vitro (Wang and Hatton, 2004). A summary of these electrical features of OT-evoked bursts is shown in Figure $2 C$.

To verify the specificity of OT in burst generation, we performed the following control experiment to establish the base rate of bursts occurring in the absence of any special stimulation. During 60-70 min recordings from 30 OT neurons, no spontaneous bursts were observed (Fig. $1 A)$. We then confirmed the mediation by OTRs in OT-evoked bursts. After application of a selective OT antagonist $[(\beta-$ mercapto- $\beta, \beta$-cyclopentamethylenepropionyl $^{1}$, O-Me-Tyr ${ }^{2}$, Orn $\left.^{8}\right)$-OT] (1 $\mu \mathrm{M} ; 10 \mathrm{~min}$ before OT application), OT failed to evoked bursts in 20 of 20 OT neurons.

\section{Synaptic transmission}

Although the excitatory actions of OT (10 pM for $10 \mathrm{~min}$ ) have been observed to depend heavily on presynaptic inputs (Wang and Hatton, 2006), the influence of local neural circuits in burst generation has not been previously explored. Here, we first examined the involvement of fast glutamatergic inputs on burst occurrence. In the presence of blockers of ionotropic glutamate receptors, $10 \mu \mathrm{M}$ 6-cyano-7nitroquinoxaline-2,3-dione (CNQX) and $100 \mu \mathrm{M} \mathrm{D}(-)$-amino5-phosphonopentanoic acid (APV), no bursts were evoked by OT (10 pM for $30 \mathrm{~min} ; n=18$ ) (Fig. $3 A$ ). In contrast with glutamate actions, blocking $\mathrm{GABA}_{\mathrm{A}}$ receptors with $20 \mu \mathrm{m}$ bicuculline significantly increased the basal firing rate and occasionally triggered a burst (2 of 19 OT neurons). However, the presence of bicuculline did not drastically influence the incidence ( 4 of 15 OT neurons) of OT-evoked bursts (Fig. $3 B$ ). These results clearly indicate the essential role of ionotropic glutamatergic synaptic inputs in OT-evoked bursts.

Similar to the action of blocking ionotropic glutamate receptors, blocking synaptic vesicle release by pretreatment with tetanus toxin (10 nM for $1-1.5 \mathrm{~h} ; n=16$ ) also blocked the burstevoking effect of OT (Fig. $3 C$ ), although postsynaptic neurons could still be excited by OT at a delayed time course. Tetanus toxin also suppressed IPSCs and EPSCs, the same results as those shown in our recent report (Wang and Hatton, 2006). Because OT neurons and SON astrocytes are themselves probably glutamatergic (Ponzio et al., 2006), the blockade of glutamatergic transmission and synaptic vesicle release may also include components from OT neurons and astrocytes.

An essential question for the role of EPSCs in OT-evoked bursts is how blocking glutamatergic synaptic transmission also blocked the burst if OT itself inhibits EPSCs. OT has inhibitory effects on evoked or tonic miniature EPSCs (Hirasawa et al., 2001), whereas ionotropic glutamatergic synaptic inputs are a prerequisite for OT-evoked burst or suckling-elicited OT secretion (Parker and Crowley, 1993b). This apparent contradiction is likely because of different regulation of OT on different EPSC patterns. In normal aCSF, OT neurons showed various EPSC patterns: tonic EPSCs, periodic clusters of EPSCs, and interme- diate patterns of EPSCs. A clustering EPSC was defined as a transient (at least $0.3 \mathrm{~s}$ duration) increase in EPSC frequency, with a minimal average frequency of $4 \mathrm{~Hz}$ and instantaneous frequency of $20 \mathrm{~Hz}$ (usually $>20 \mathrm{~Hz}$ ), which were at least two times and 10 times, respectively, more than the average EPSC frequency immediately before the cluster. In response to OT (10 pM for 10 $\min )$, there was a significant reduction $(n=12 ; p<0.05)$ in the frequency of tonic EPSCs (Fig. 3D1). Apparently, however, clusters of EPSCs are modulated independently of the tonic EPSCs. The number of OT neurons showing EPSC clusters (Fig. 3D2) increased significantly from 0 neurons in control to 6 of 12 neurons after OT application ( $p<0.05$ by $\chi^{2}$ test). Thus, these results suggest that OT may evoke bursts by selectively increasing EPSC clustering and suppressing the tonic EPSCs.

\section{G-protein mediation}

All known regulatory effects of OT are achieved via activation of OTRs, which are a type of GPCR. Burst-evoking effects of OT may also use this pathway. To confirm the involvement of G-protein signaling, we applied suramin, an uncoupler of G-proteins with GPCRs. Suramin $(20 \mu \mathrm{M} ; n=15)$ reduced the firing activity of OT neurons and blocked the burst-evoking effects of OT (Fig. 4A), an effect similar to intracellularly loading GDP- $\beta$-S $(n=20)$ (Fig. $4 B)$. In contrast, intracellularly injected antibody against the OT receptor C terminus $(1 \mu \mathrm{g} / \mathrm{ml})$ did not block burst generation. Three of 16 OT neurons still showed bursts. The bursts evoked during the application of this antibody, however, showed no marked $E_{\mathrm{m}}$ depolarization or spike amplitude reduction during peak firing rate (compare Figs. 2C, 4C). These results indicate that both presynaptic and postsynaptic signals are involved in OT-evoked burst expression but that they 
A
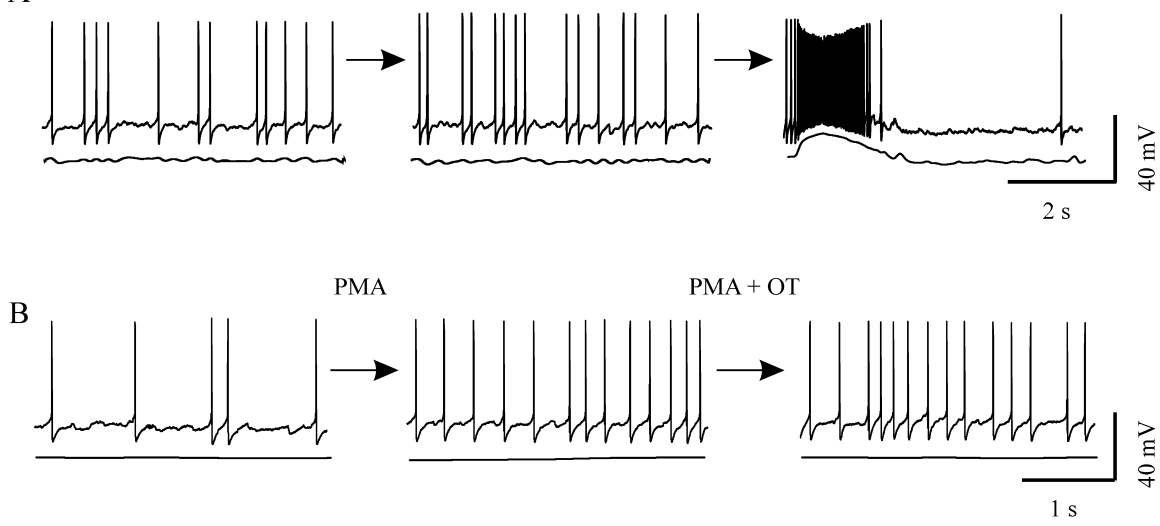

$\mathrm{C}$

Thaps.

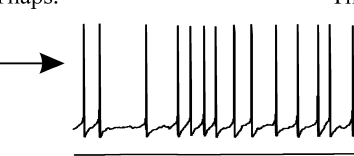

Thaps. + OT
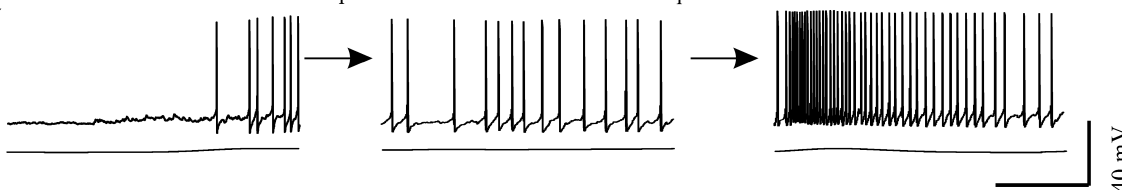

$1 \mathrm{~s}$

$\mathrm{D}$

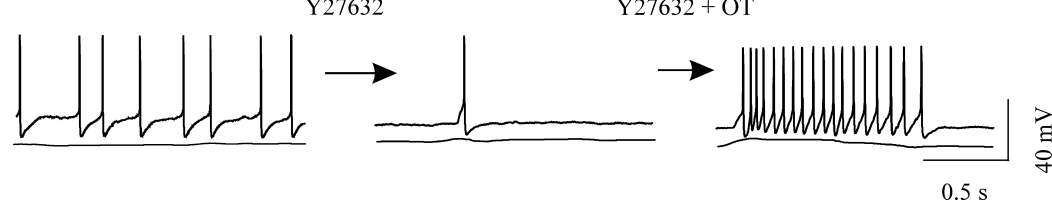

Figure 5. $G \alpha_{q / 11}$ signaling and $0 \mathrm{~T}$-evoked bursts. $\boldsymbol{A}-\boldsymbol{D}$, Effects of agents that simulate or block potential $\mathrm{G} \alpha_{\mathrm{q} / 11}$ signaling on burst generation. $\boldsymbol{A}$, Blocking phospholipase $\mathrm{C}$ with $5 \mu \mathrm{m}$ U73122 from $10 \mathrm{~min}$ before $0 \mathrm{~T}$ did not block $0 \mathrm{~T}$-evoked bursts. $\boldsymbol{B}$, Using PMA (1 $\mu \mathrm{m}$ for $10 \mathrm{~min}$ ) to activate protein kinase ( neither triggered nor facilitated 0T-evoked bursts. C, Applying thapsigargin (Thaps.; $200 \mathrm{~nm}$ for $30 \mathrm{~min}$ ) to deplete $0 \mathrm{~T}$ - and $\mathrm{IP}_{3}$-sensitive internal $\mathrm{Ca}^{2+}$ stores did not block 0T-evoked bursts. D, OT-evoked bursts were intact after blocking activation of RhoA/Rho kinase with $10 \mu \mathrm{m}$ Y27632.

play different roles in OT-evoked burst formation. The former may be responsible for triggering burst onset, whereas the latter is more involved in sculpting specific features of the burst (e.g., the $E_{\mathrm{m}}$ and spike changes). Together with the data on synaptic transmission, these results suggest that some secondary G-proteinmodulating substances other than glutamate are involved in the total burst-evoking actions of OT.

OTRs can couple to both $\mathrm{G}_{\mathrm{i} / \mathrm{o}^{-}}$and $\mathrm{G}_{\mathrm{q} / 11}$-type $\mathrm{G}$-proteins (Hoare et al., 1999). To identify the potential role of $\mathrm{G}_{\mathrm{i} / \mathrm{o}^{-}}$ proteins, we pretreated slices with pertussis toxin (PTX) $(1 \mu \mathrm{g} /$ $\mathrm{ml} ;>6 \mathrm{~h}$ ) and examined the effect of blocking $\mathrm{G}_{\mathrm{i} / \mathrm{o}}$-proteins on the burst-evoking effect of OT. PTX pretreatment did not erase the preburst firing; OT still caused bursts (in 5 of 16 OT neurons). In contrast to the control condition, after PTX, OT-evoked bursts showed obvious prolonged ending portions (up to $20 \mathrm{~s}$ ); the depolarized $E_{\mathrm{m}}$ returned to resting condition slowly, and no clearcut postburst inhibition was detected (Fig. 4D). This result suggests that $\mathrm{G} \alpha_{\mathrm{i} / \mathrm{o}}$ subunits are unlikely to trigger bursts but may participate in burst termination.

\section{$\mathrm{G} \boldsymbol{\alpha}_{\mathrm{q} / 11}$ subunit and bursts}

$\mathrm{G} \alpha_{\mathrm{q} / 11}$ subunit signaling has been generally accepted as the major event in OT signaling, but its function in OT-evoked bursts remains in question. To examine the involvement of $\mathrm{G} \alpha_{\mathrm{q} / 11}$ phospholipase C- $\beta$ (PLC- $\beta$ ) pathway in OT actions, 1-[6-([17 $\beta$ methoxyestra-1,3,5(10)-trien-17-yl]amino)hexyl]-1 $H$-pyrrole2,5-dione (U73122) (5 $\mu \mathrm{M})$, an inhibitor of PLC, was applied in the bath starting $10 \mathrm{~min}$ before OT. Despite the presence of
U73122 and its inhibition of OT excitatory effects, five bursts from four neurons $(n=$ 20) were evoked after application of OT. Although three of the bursts displayed no spike broadening or dramatic $E_{\mathrm{m}}$ depolarization at peak firing rate, typical bursts were also observed (Fig. 5A). This result suggests that the $\mathrm{G} \alpha_{\mathrm{q} / 11}-\mathrm{PLC}$ pathway may be partially involved in changes in spike shape and $E_{\mathrm{m}}$ in OT-evoked bursts but play no major role in triggering bursts.

Activation of $\mathrm{G} \alpha_{\mathrm{q} / 11}$-PLC pathway results in the formation of diacylglycerol (DAG) and inositol trisphosphate $\left(\mathrm{IP}_{3}\right)$ (Evans et al., 1997). Using phorbol 12myristate 13 -acetate (PMA) ( $1 \mu \mathrm{M}$ for 10 min) to simulate the effect of DAG in activation of protein kinase $C$ partially mimicked the effects of OT (i.e., an initial increase in firing rate and a subsequent spike-frequency reduction). However, PMA did not evoke but blocked OTevoked bursts $(n=12 ; p<0.05$ compared with OT actions) (Fig. $5 B$ ), suggesting negative feedback of protein kinase $C$ at the OTR level. In parallel with the DAGrelated signaling system, we also examined the involvement of the $\mathrm{IP}_{3}-\mathrm{Ca}^{2+}$ pathway in OT-evoked bursts. Thirty minutes after bath application of thapsigargin (200 nM), a $\mathrm{Ca}^{2+}$ uptake inhibitor for OT- and $\mathrm{IP}_{3}{ }^{-}$ sensitive internal $\mathrm{Ca}^{2+}$ stores, OT could still evoke bursts in two of nine OT neurons (Fig. 5C). Intracellularly loading BAPTA did not eliminate OT-evoked bursts. In 2 of 11 such neurons, OT still evoked bursts. These results suggest that intracellular $\mathrm{Ca}^{2+}$ mobilization is not essential for burst generation.

Activation of $\mathrm{G} \alpha_{\mathrm{q} / 11}$ subunits may also activate RhoA/Rho kinase (ROCK) (Vogt et al., 2003). To investigate possible mediation by this pathway, we applied $50 \mu \mathrm{M}(R)-(+)$-trans-4-(1aminoethyl)- $N$-(4-pyridyl)-cyclohexanecarboxamide (Y27632) for $10-15$ min to block this kinase before OT was added. Although blocking ROCK tended to reduce the basal firing rate in eight OT neurons, Y27632 blocked neither OT excitatory effects on basal firing rate nor OT-evoked bursts. In two of these neurons, bursts were still evoked (Fig. 5D), ruling out the possibility that ROCK functions as a major mediator in OT-evoked bursts.

\section{Signaling pathway of $\mathrm{G} \boldsymbol{\beta} \boldsymbol{\gamma}$ subunits}

In parallel with $\mathrm{G} \alpha_{\mathrm{q} / 11}$ signals, signaling pathways triggered by G-protein $\beta \gamma$ subunits also mediate OT actions in peripheral tissues (Zhong et al., 2003). Most interestingly, key enzymes for prostaglandin [secondary mediators of OT excitatory actions (Wang and Hatton, 2006)] synthesis, phospholipase $\mathrm{A}_{2}$ (Jelsema and Axelrod, 1987) and ERK1/2 (Goubaeva et al., 2003; Zhong et al., 2003), can also be activated by the $G \beta$ subunit. Therefore, we further examined the effects of activating G $\beta \gamma$ subunits on OT neuronal activity. Bath application $(0.2-0.5 \mu \mathrm{M}$ for $10 \mathrm{~min})$ of the G-protein $\beta \gamma$-activating peptide mSIRK (Goubaeva et al., 2003; Malik et al., 2005) triggered bursts in 7 of 25 OT neurons (Fig. 6A). However, intracellularly loading antibody against $\mathrm{G} \beta$ subunits $(1 \mu \mathrm{g} / \mathrm{ml})$ inhibited burst generation under OT stimu- 
lation (Fig. 6B). Of 12 neurons tested, none showed bursts. Because bursts could be evoked in the OT neurons that were loaded with OTR C-terminal antibody, this evidence supports a specific action of $\mathrm{G} \beta$ antibody. Consistent with the effects of OT, mSIRK also differently modulated different patterns of EPSCs. Although $\operatorname{mSIRK}(0.2 \mu \mathrm{M}$ for $10 \mathrm{~min})$ reduced the frequency of tonic EPSCs, it also caused EPSC clustering in three of eight OT neurons within $10 \mathrm{~min}$ after $\mathrm{mSIRK}$ application (Fig. 6C). These results suggest that activation of $\mathrm{G} \beta \gamma$ subunits plays a major role in burst generation.

Increasingly, studies of $\mathrm{G} \beta \gamma$ subunits present complex profiles of their functions. It is generally believed that free $\mathrm{G} \beta \gamma$ subunits exert their influence via Src family kinase (SFK) and phosphatidylinositol 3-kinase (PI3 kinase) (Viard et al., 1999; Macrez et al., 2001; Quignard et al., 2001). In the hypothalamus, SFK (Charpantier et al., 2005) and PI3 kinase (CardonaGomez et al., 2002; Sahu, 2003; Lin et al., 2004) are functionally active. If $\mathrm{G} \beta \gamma$ subunits mediate OT actions, SFK and PI3 kinase may also be involved. In the presence of SFK inhibitor (2,3-dihydro- $N, N$-dimethyl-2-oxo-3-[(4,5,6,7-tetrahydro$1 H$-indol-2-yl)methylene]- $1 H$-indole5-sulfonic acid [Su6656]; 2-10 $\mu \mathrm{M})$, $\operatorname{mSIRK}(n=12)$ and OT $(n=12)$ both failed to evoke bursts (Fig. 6D,E). However, application of wortmannin (100 $\mathrm{nM} ; 10$ min before OT) to block the activation of PI3 kinase did not block OTevoked bursts. Three of 11 OT neurons exhibited bursts (Fig. $6 F$ ). These results suggest that $\mathrm{G} \beta \gamma$ subunits trigger the bursts via SFK but not PI3 kinase.

\section{Activation of OTR-associated}

$\mathrm{G} \boldsymbol{\alpha}_{\mathrm{q} / 11}$ subunits and mobilization of G $\boldsymbol{\beta} \gamma$ subunits during suckling

One question about these signal transduction pathways is whether burst-regulating processes seen in vitro are also involved in suckling-induced activation of OT neurons. To answer this question, coimmunoprecipitation and immunocytochemistry were performed on SONs from two groups of lactating rats, one before and one after suckling. We first confirmed the interactions between OTRs and $\mathrm{G} \alpha_{\mathrm{q} / 11}$ or $\mathrm{G} \beta$ signaling. In Western blot, suckling did not markedly influence the expression of either $\mathrm{G} \alpha_{\mathrm{q} / 11}$ or $\mathrm{G} \beta$ subunits (Fig. 7A). However, after immunoprecipitating $\mathrm{G} \alpha_{\mathrm{q} / 11}(n=3)$ or $\mathrm{G} \beta$ subunits $(n=1)$, using Western blots detected a significant reduction in their association with OTRs (Fig. 7B1), indicating the mobilization of OTR-associated $\mathrm{G} \alpha$ q/11 and $\mathrm{G} \beta$ subunits. Then, we confirmed the mobilization of $\mathrm{G} \alpha_{\mathrm{q} / 11}$-associated $\mathrm{G} \beta \gamma$ subunits by detecting $\mathrm{G} \beta$ or $\mathrm{G} \alpha_{\mathrm{q} / 11}$ subunits in the immunoprecipitation of $\mathrm{G}_{\alpha_{\mathrm{q} / 11}}(n=3)$ or $\mathrm{G} \beta(n=2)$ subunits. A dramatic dissociation of $\mathrm{G} \beta$ subunits from $\mathrm{G} \alpha_{\mathrm{q} / 11}$ subunits occurred during suckling (Fig. 7B1). Because the two coimmunoprecipitations generated similar results, we pooled these data and found a significant $(n=5 ; p<0.05)$ reduction in their association. This was further confirmed by the different spatial distribution of $\mathrm{G} \alpha_{\mathrm{q} / 11}$ subunits from $\mathrm{G} \beta$ subunits in immunocytochemistry (Fig. 8).

In judging relative immunostaining intensity, all images were taken under the same conditions during acquisition in 20 SONs from five pairs of animals. Relative changes in the intensity of immunostaining across the central section of nuclei were detected and expressed as a percentage of the control (i.e., nonsuckling and $\mathrm{G} \alpha_{\mathrm{q} / 11}$ subunit). Before suckling stimulation, both $\mathrm{G} \alpha_{\mathrm{q} / 11}$ and $\mathrm{G} \beta$ subunits were detected in the cytosol, at the membrane of OT neurons and non-OT neuronal components (i.e., VP neurons, astrocytes, and neuropil). Dense staining was seen at the membrane, whereas staining in nuclei was barely detected above the background level (i.e., nonprimary control staining). After suckling stimulation, $\mathrm{G} \alpha_{\mathrm{q} / 11}$ expression in the cytosol, membrane, and whole area of the SON tended to be reduced, significantly ( 8 of $10 ; 86 \pm 8.2 \%$ of nonsuckling) at membrane sections. 

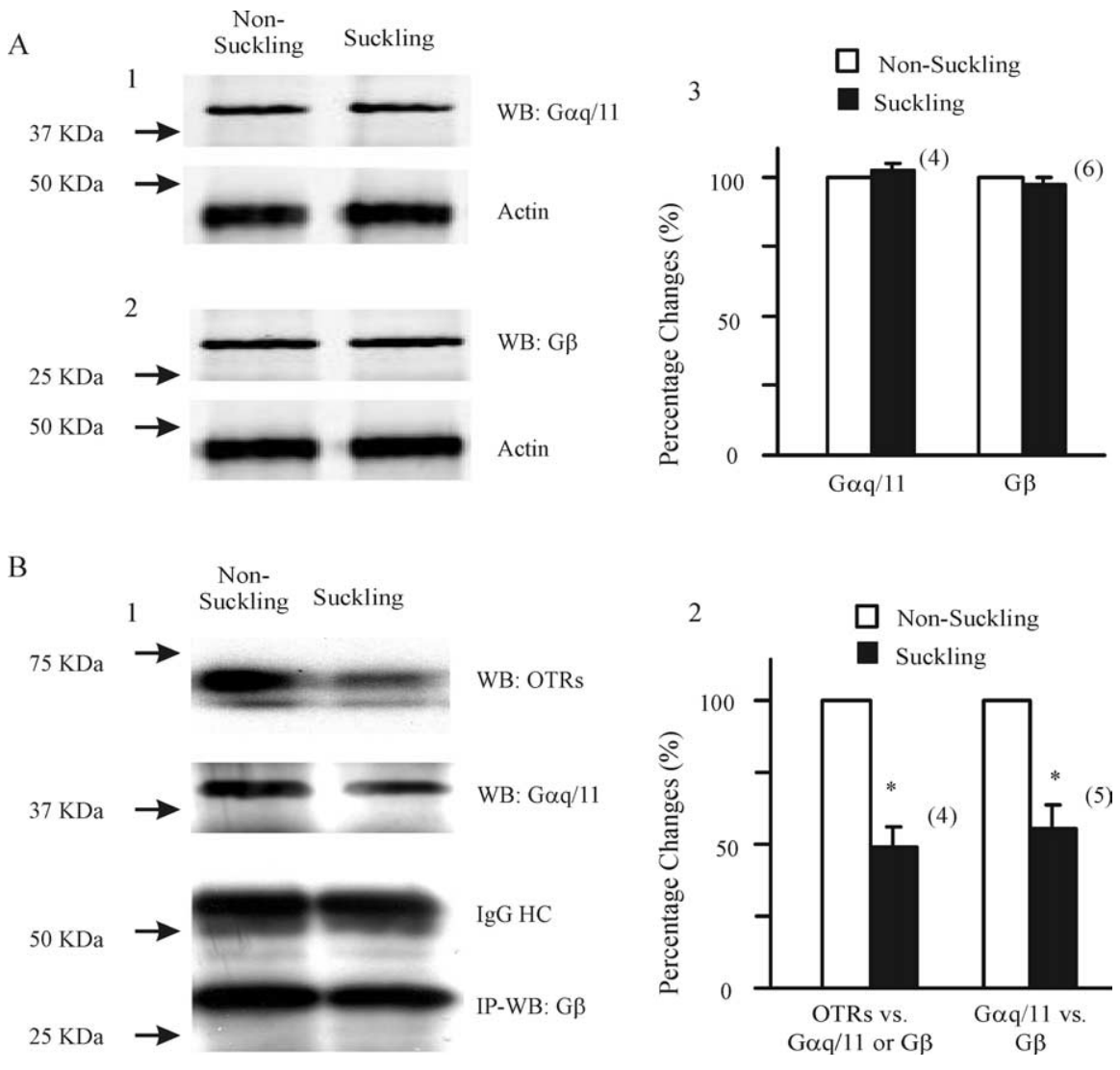

Figure 7. Suckling mobilized $0 T R s$ and $\mathrm{G}_{\mathrm{q} / 11}$-proteins in lactating rats. $\boldsymbol{A}$, Western blot (WB) of $\mathrm{G} \alpha_{\mathrm{q} / 11}$ and $\mathrm{G} \beta$ subunits in nonsuckling and suckling rats. $\boldsymbol{A 1}, \boldsymbol{A 2}$, Examples of the effects of suckling on $\mathrm{G} \alpha_{\mathrm{q} / 11}$ and $\mathrm{G} \beta$ expression, in which actin was used as loading control (bottom bands). A3, Summary graph of suckling effects on $G \alpha_{\mathrm{q} / 11}$ and $\mathrm{G} \beta$ expression, respectively. The numbers in parentheses indicate pairs of observations. $\boldsymbol{B}$, Dissociation of $\mathrm{G} \alpha_{\mathrm{q} / 11}$ subunit from OTRs and $\mathrm{G} \beta$ subunit. $\boldsymbol{B}$, Immunoprecipitation (IP) of $\mathrm{G} \beta$ subunit with rabbit antibody (1.5 $\mu \mathrm{g}$ per $500 \mu$ l of total lysates) and WB detection of 0TRs (top band) and $\mathrm{G} \alpha_{\mathrm{q} / 11}$ subunits (second band). Ig $\mathrm{G}$ (third band) and $\mathrm{G} \beta$ subunits (bottom band) were used as negative control and loading control, respectively. B2, Summary graph showing the relative changes in the molecular association between 0 TRs and $\mathrm{G} \alpha_{\mathrm{q} / 11}$ $(n=3)$ or $\mathrm{G} \beta(n=1)$ subunits and between $\mathrm{G} \alpha_{\mathrm{q} / 11}$ and $\mathrm{G} \beta$ subunits $\left(n=3\right.$ for $\mathrm{G} \alpha_{\mathrm{q} / 11} \mathrm{IP} ; n=2$ for $\left.\mathrm{G} \beta \mathrm{IP}\right)$. Because the changes in the molecular association of OTRs with $\mathrm{G} \alpha_{\mathrm{q} / 11}$ or with $\mathrm{G} \beta$ subunits were similar to those in the association between IP of $G \alpha_{\mathrm{q} / 11}$ and $\mathrm{G} \beta$, we pooled the data and performed paired $t$ tests $\left({ }^{*} p<0.05\right)$ after square-root transformation of raw band densities. $\mathrm{HC}$, Heavy chain; nonsuckling, after separation of mothers from 10 pups for 4 h; suckling, suckling of 10 pups for $\sim 10$ min within 1 min after occurrence of milk-ejection reflex after a separation for $4 \mathrm{~h}$.

This may reflect internalization and decomposition of $\mathrm{G} \alpha_{\mathrm{q} / 11}$ subunit after activation. Opposite to the changes in $\mathrm{G} \alpha_{\mathrm{q} / 11}$ subunits, intensity of $\mathrm{G} \beta$ subunits tended to increase in all areas except at the membrane. Significant increases were observed in the cytosol ( 8 of 10$)$, nuclei $(n=10)$, and the whole SON $(n=$ $10)$. Relatively, suckling significantly increased the intensity differences between $\mathrm{G} \alpha_{\mathrm{q} / 11}$ subunit and $\mathrm{G} \beta$ subunit, particularly at the cytosol and the membrane, supporting dissociation between the two GPCR subunits during suckling.

\section{Discussion}

Here, we present data showing that burst firing in OT neurons in brain slices can be evoked from adult animals by OT. This action of OT is dependent on both excitatory synaptic drive and postsynaptic activation of GPCRs via OTRs. Both $\mathrm{G} \alpha_{\mathrm{q} / 11}$ and $\mathrm{G} \beta \gamma$ subunits are involved in burst generation; the latter plays a dominant role in burst onset.

\section{OT-evoked excitation and bursts}

Excitatory effects of OT have been explored extensively [for review, see Crowley and Armstrong (1992), Wakerley et al. (1994), and Leng et al. (1999)], but this is the first identification of the mechanisms underlying the burst-evoking potency of OT in lactating animals. In contrast to most of the previous work, the present study and a few others used effective OT concentrations (Kow et al., 1991; Kuriyama et al., 1993; Wang et al., 2006) equal to or lower than the reported physiological level (Neumann et al., 1993). Several possibilities may account for these actions. First, OTRs have different affinity subtypes (for review, see Gimpl and Fahrenholz, 2001), which may allow low concentrations of exogenous OT to exert effects via highaffinity and low-volume receptors. Second, OT neurons may have many different functional microdomains, which render OT neurons especially responsive to exogenous OT. Somatodendritic release of OT (Ludwig et al., 2002) likely occurs pointto-point or in a region-specific manner (e.g., dendritic region superior to somatic region), not as an action that is equivalent across the entire membrane. Thus, the membrane close to the release sites may receive stimulation differently from remote areas. Excited and inhibited microdomains would be intermingled in the same cell and averaged to mask many locally dramatic changes. However, exogenous OT would globally stimulate all membrane domains in which OTRs exist, elicit extensive responses, and override the influence of individual microdomains. Finally, the presence of astrocytes and their different contacts with neurons (Hatton, 2004) may also separate the actions of endogenous and exogenous OT. Patch clamping will first remove the glial cover before whole-cell conformation takes place. Thus, in contrast to the in vivo situation or the OT neurons deep in the slices, patch-clamped OT neurons more easily receive the global influence of exogenous agents, even at much lower concentrations than those in vivo.

In the present study, burst firing failed to occur spontaneously in any of the 30 control OT neurons that were each recorded for $1 \mathrm{~h}$ or more, suggesting that the burst base rate was effectively zero. Bath application of OT, however, evoked bursts from 8 of 30 OT neurons within $20 \mathrm{~min}$. Because the specific OT antagonist eliminated all OT-evoked bursts, these results indicate the specificity of OT to initiate bursts under the present experimental conditions. Electrical features of these bursts were similar to those in our previous study using a different protocol (Wang and Hatton, 2004), suggesting that they represent common features of bursts in OT neurons. In the present work, many previously unknown membrane electrical features of bursts were explored, including spike amplitude reduction, spike broadening, and changes in the AHP, etc. These findings provided a solid background from which to predict the ionic mechanisms underlying the bursts, as discussed previously (Wang and Hatton, 2004). Differences between these bursts and those recorded during suckling (Wakerley and Lincoln, 1973) are also noteworthy: re- 
current bursts from one neuron were few; durations of these bursts were short; and burst amplitudes (number of spikes per burst) were lower. However, most of these features were also identified from studies in lactating animals (Moos et al., 1989; Wang et al., 1997), in which it was found that interhemispheric section between bilateral hypothalami did reduce the amplitude and regularity of bursts. Thus, our results may reflect physiological regulation of the milk-ejection bursts at the level of local circuits.

\section{Dominance and source of $\mathrm{G} \boldsymbol{\beta} \boldsymbol{\gamma}$ subunits in OT-evoked bursts}

Although $\mathrm{G}_{\mathrm{i} / \mathrm{o}}$-proteins can also be activated by OTRs (Hoare et al., 1999), the failure of PTX in blocking burst generation points to the importance of $\mathrm{G}_{\mathrm{q} / 11^{-}}$ proteins in burst generation. However, strong involvement of PLC signaling and ROCK was unlikely from the present findings. On the contrary, G $\beta \gamma$ subunits can be considered to be the dominant signaling pathway in OT-evoked bursts. This is supported by the facts that an intracellularly applied G $\beta$ antibody blocked OTevoked bursts and that a $\mathrm{G} \beta \gamma$ activator evoked bursts, whereas blocking $\mathrm{G} \alpha_{\mathrm{q} / 11}$ signaling did not block burst expression. The G $\beta \gamma$ subunits may function via SFK but not PI3 kinase pathway, as indicated in our results. SFK could link G $\beta \gamma$ subunits to ERK1/2 and phospholipase $A_{2}$ (Buresi et al., 2002), influencing many cellular functions. It is noteworthy that OTR$\mathrm{G} \alpha_{\mathrm{q} / 11}-\mathrm{PLC}$ signaling is likely responsible for membrane electrical features uniquely disclosed by patch-clamp methods in vitro (Wang and Hatton, 2004).

In the present work, blocking OTRs at the $\mathrm{C}$ terminus modified but did not block OT-evoked bursts, highlighting the possibility of $\mathrm{G} \alpha_{\mathrm{i} / \mathrm{o}}$ mediation (Hoare et al., 1999). That PTX pretreatment did not block OT-evoked bursts, however, suggests that the $\mathrm{G} \beta \gamma$ subunits are not necessarily linked to $\mathrm{G} \alpha_{\mathrm{i} / \mathrm{o}}$. These findings are in agreement with a previous report (Tsunoda and Owyang, 1994 ) showing that a $G \beta$ subunit from a non $-G_{i / o}$ source activates phospholipase $\mathrm{A}_{2}$, a downstream effector of OTR activation (Goff, 2004). One possible link between $\mathrm{G} \alpha_{\mathrm{q} / 11}$ signaling and $\mathrm{G} \beta \gamma$ signaling can be achieved via excitation and $\mathrm{Na}^{+}$retention in neurons. Increased intracellular $\left[\mathrm{Na}^{+}\right]$can also activate $\mathrm{G} \beta \gamma$ subunits and influence multiple cellular functions [e.g., N-type voltage-dependent $\mathrm{Ca}^{2+}$ channels (Blumenstein et al., 2004) and phospholipase $\mathrm{A}_{2}$ activity (Jelsema and Axelrod, 1987)]. Newly synthesized G $\beta \gamma$ subunits, highlighted by the cytosolic G $\beta$ expression during suckling, could not be excluded.

Dose-dependent effects were observed in the actions of mSIRK. Lower doses often caused periodic excitation and inhibition of basal firing rate and $E_{\mathrm{m}}$, whereas higher doses $(1-2 \mu \mathrm{M})$ led to persistent inhibition and no burst firing. Thus, it seems that only at an appropriate level of activation of $\mathrm{G} \beta \gamma$ subunits could OT trigger bursts.

\section{Sites of OT action}

The excitatory actions of OT are achieved via activation of OTRs (Wang and Hatton, 2006) and $\mathrm{G}_{\mathrm{q} / 11}$-proteins on both presynaptic and postsynaptic neurons. Presynaptic involvement was shown by OT-induced reduction of tonic excitatory input (Pittman et al., 2000) and increased transient EPSCs. Postsynaptic actions are highlighted by intracellular G-protein blockade also blocking OT-evoked bursts. Presynaptically, the role of metabotropic glutamate receptors in OT-modulated synaptic activity remains to be explored. In addition to modulating glutamate release, OT can generate some endogenous burst-evoking agents (e.g., prostaglandins) (Hatton and Wang, 2005; Wang and Hatton, 2006). OT can also act in an autocrine manner to increase spike duration within a burst and induce $E_{\mathrm{m}}$ depolarization at postsynaptic levels. Involvement of purinergic actions cannot be excluded, because suramin is also a potent P2X and 
P2Y receptor inhibitor. In addition to glutamate, GABAergic transmission could contribute to OT-evoked bursts. Blockade of inhibitory actions of GABA may aid in the summation of burstevoking signals; however, this seems minor compared with glutamate actions. Finally, astrocytes may also contribute to the burst-evoking effects of OT. This is supported by the observation of activation of $\mathrm{G} \beta$ subunits in astrocytic components in our immunostaining results.

The dominant mediation of $\mathrm{G} \beta \gamma$ subunits is consistent with the inhibitory action of OT on glutamate release at presynaptic terminals. $\mathrm{G} \beta \gamma$ subunits can inhibit the activity of $\mathrm{N}$-type $\mathrm{Ca}^{2+}$ channels (Blumenstein et al., 2004), which is closely related to the inhibitory actions of OT on EPSCs (Hirasawa et al., 2001). Inhibition of the N-type $\mathrm{Ca}^{2+}$ channels did not influence AMPAinduced OT release (Parker and Crowley, 1993a). The results presented here are consistent with mobilization of $\mathrm{G} \beta \gamma$ subunits simultaneously occurring at both presynaptic and postsynaptic sites in response to OT.

A seemingly contradictory phenomenon is the general inhibitory effect of OT/mSIRK on EPSCs and the dependence of OTevoked bursts on glutamate/AMPA inputs. However, a likely answer was achieved by classifying EPSCs into tonic and clustering components. Both OT and mSIRK suppressed the tonic components of EPSCs and increased the incidence of EPSC clustering. In terms of burst firing, EPSC clustering obviously provides more driving force than do tonic EPSCs. Reduced tonic EPSCs may actually create an optimal condition for burst generation. For instance, in response to glutamate stimulation, some cellular signals [e.g., cyclooxygenase 2 (Wang and Hatton, 2006) and ERK1/2 (Paul et al., 2003)] were downregulated rather than upregulated, a condition that exists at later stages of OT actions. Reduced tonic EPSCs/glutamatergic inputs will reduce this inhibition (e.g., by group III metabotropic glutamate receptors) and resensitize OT neurons to novel and bolus glutamate stimuli, making burst firing more probable.

\section{Implication of OT-evoked bursts via $\mathrm{G} \beta \boldsymbol{\gamma}$ subunits}

Classically, knowledge about G $\beta \gamma$ subunits in neuronal functions is quite limited; thus it is also in OT neurons. Using membranepermeable $\mathrm{G} \beta \gamma$ subunit activators and other approaches, combining slices with intact animal data, we demonstrated the functions of $\mathrm{G} \alpha_{\mathrm{q} / 11}$-associated $\mathrm{G} \beta \gamma$ subunits in the burst firing in OT neurons. Considering the similarity among neuronal signaling mechanisms, the same regulatory mechanisms may exist widely in the brain.

\section{References}

Bealer SL, Crowley WR (1999) Neurotransmitter interaction in release of intranuclear oxytocin in magnocellular nuclei of the hypothalamus. Ann NY Acad Sci 897:182-191.

Blumenstein Y, Maximyuk OP, Lozovaya N, Yatsenko NM, Kanevsky N, Krishtal O, Dascal N (2004) Intracellular $\mathrm{Na}+$ inhibits voltagedependent $\mathrm{N}$-type $\mathrm{Ca}^{2+}$ channels by a $\mathrm{G}$ protein betagamma subunitdependent mechanism. J Physiol (Lond) 556:121-134.

Buresi MC, Buret AG, Hollenberg MD, MacNaughton WK (2002) Activation of proteinase-activated receptor 1 stimulates epithelial chloride secretion through a unique MAP kinase- and cyclo-oxygenase-dependent pathway. FASEB J 16:1515-1525.

Cardona-Gomez GP, Mendez P, Garcia-Segura LM (2002) Synergistic interaction of estradiol and insulin-like growth factor-I in the activation of PI3K/Akt signaling in the adult rat hypothalamus. Brain Res Mol Brain Res 107:80-88.

Charpantier E, Wiesner A, Huh KH, Ogier R, Hoda JC, Allaman G, Raggenbass M, Feuerbach D, Bertrand D, Fuhrer C (2005) $\alpha 7$ neuronal nicotinic acetylcholine receptors are negatively regulated by tyrosine phosphorylation and Src-family kinases. J Neurosci 25:9836-9849.
Crowley WR, Armstrong WE (1992) Neurochemical regulation of oxytocin secretion in lactation. Endocr Rev 13:33-65.

Darbon P, Tscherter A, Yvon C, Streit J (2003) Role of the electrogenic Na/K pump in disinhibition-induced bursting in cultured spinal networks. J Neurophysiol 90:3119-3129.

Dunin-Barkowski WL, Escobar AL, Lovering AT, Orem JM (2003) Respiratory pattern generator model using $\mathrm{Ca}++$-induced $\mathrm{Ca}++$ release in neurons shows both pacemaker and reciprocal network properties. Biol Cybern 89:274-288.

Evans JJ, Forrest-Owen W, McArdle CA (1997) Oxytocin receptormediated activation of phosphoinositidase $\mathrm{C}$ and elevation of cytosolic calcium in the gonadotrope-derived alphaT3-1 cell line. Endocrinology 138:2049-2055.

Freund-Mercier MJ, Richard P (1984) Electrophysiological evidence for facilitatory control of oxytocin neurones by oxytocin during suckling in the rat. J Physiol (Lond) 352:447-466.

Gimpl G, Fahrenholz F (2001) The oxytocin receptor system: structure, function, and regulation. Physiol Rev 81:629-683.

Goff AK (2004) Steroid hormone modulation of prostaglandin secretion in the ruminant endometrium during the estrous cycle. Biol Reprod 71:11-16.

Goubaeva F, Ghosh M, Malik S, Yang J, Hinkle PM, Griendling KK, Neubig RR, Smrcka AV (2003) Stimulation of cellular signaling and G protein subunit dissociation by $\mathrm{G}$ protein betagamma subunit-binding peptides. J Biol Chem 278:19634-19641.

Hatton GI (1990) Emerging concepts of structure-function dynamics in adult brain: the hypothalamo-neurohypophysial system. Prog Neurobiol 34:437-504.

Hatton GI (2004) Morphological plasticity of astroglial/neuronal interactions: functional implications. In: Glial neuronal signaling (Hatton GI, Parpura V, eds), pp 99-124. Boston: Kluwer Academic.

Hatton GI, Wang Y-F (2005) Signal transduction pathway underlying oxytocin-evoked burst firing in oxytocin neurons. Soc Neurosci Abstr 31:993.8.

Hirasawa M, Kombian SB, Pittman QJ (2001) Oxytocin retrogradely inhibits evoked, but not miniature, EPSCs in the rat supraoptic nucleus: role of $\mathrm{N}$ - and P/Q-type calcium channels. J Physiol (Lond) 532:595-607.

Hoare S, Copland JA, Strakova Z, Ives K, Jeng YJ, Hellmich MR, Soloff MS (1999) The proximal portion of the $\mathrm{COOH}$ terminus of the oxytocin receptor is required for coupling to $\mathrm{g}(\mathrm{q})$, but not $\mathrm{g}(\mathrm{i})$. Independent mechanisms for elevating intracellular calcium concentrations from intracellular stores. J Biol Chem 274:28682-28689.

Jelsema CL, Axelrod J (1987) Stimulation of phospholipase A2 activity in bovine rod outer segments by the beta gamma subunits of transducin and its inhibition by the alpha subunit. Proc Natl Acad Sci USA 84:3623-3627.

Jourdain P, Israel JM, Dupouy B, Oliet SH, Allard M, Vitiello S, Theodosis DT, Poulain DA (1998) Evidence for a hypothalamic oxytocin-sensitive pattern-generating network governing oxytocin neurons in vitro. J Neurosci 18:6641-6649.

Kow LM, Johnson AE, Ogawa S, Pfaff DW (1991) Electrophysiological actions of oxytocin on hypothalamic neurons in vitro: neuropharmacological characterization and effects of ovarian steroids. Neuroendocrinology 54:526-535.

Kuriyama K, Nakashima T, Kawarabayashi T, Kiyohara T (1993) Oxytocin inhibits nonphasically firing supraoptic and paraventricular neurons in the virgin female rat. Brain Res Bull 31:681-687.

Leng G, Brown CH, Russell JA (1999) Physiological pathways regulating the activity of magnocellular neurosecretory cells. Prog Neurobiol $57: 625-655$.

Lin SY, Cui H, Yusta B, Belsham DD (2004) IGF-I signaling prevents dehydroepiandrosterone (DHEA)-induced apoptosis in hypothalamic neurons. Mol Cell Endocrinol 214:127-135.

Ludwig M, Sabatier N, Bull PM, Landgraf R, Dayanithi G, Leng G (2002) Intracellular calcium stores regulate activity-dependent neuropeptide release from dendrites. Nature 418:85-89.

Macrez N, Mironneau C, Carricaburu V, Quignard JF, Babich A, Czupalla C, Nurnberg B, Mironneau J (2001) Phosphoinositide 3-kinase isoforms selectively couple receptors to vascular L-type $\mathrm{Ca}(2+)$ channels. Circ Res 89:692-699.

Malik S, Ghosh M, Bonacci TM, Tall GG, Smrcka AV (2005) Ric-8 enhances $\mathrm{G}$ protein $\beta \gamma$-dependent signaling in response to $\beta \gamma$-binding peptides in intact cells. Mol Pharmacol 68:129-136. 
Moos F, Poulain DA, Rodriguez F, Guerne Y, Vincent JD, Richard P (1989) Release of oxytocin within the supraoptic nucleus during the milk ejection reflex in rats. Exp Brain Res 76:593-602.

Neumann I, Russell JA, Landgraf R (1993) Oxytocin and vasopressin release within the supraoptic and paraventricular nuclei of pregnant, parturient and lactating rats: a microdialysis study. Neuroscience 53:65-75.

Parker SL, Crowley WR (1993a) Stimulation of oxytocin release in the lactating rat by central excitatory amino acid mechanisms: evidence for specific involvement of R,S-alpha-amino-3-hydroxy-5-methylisoxazole-4propionic acid-sensitive glutamate receptors. Endocrinology 133:2847-2854.

Parker SL, Crowley WR (1993b) Stimulation of oxytocin release in the lactating rat by a central interaction of alpha 1-adrenergic and alpha-amino3-hydroxy-5-methylisoxazole-4-propionic acid-sensitive excitatory amino acid mechanisms. Endocrinology 133:2855-2860.

Paul S, Nairn AC, Wang P, Lombroso PJ (2003) NMDA-mediated activation of the tyrosine phosphatase STEP regulates the duration of ERK signaling. Nat Neurosci 6:34-42.

Pittman QJ, Hirasawa M, Mouginot D, Kombian SB (2000) Neurohypophysial peptides as retrograde transmitters in the supraoptic nucleus of the rat. Exp Physiol 85:139S-143S.

Ponzio TA, Ni Y, Montana V, Parpura V, Hatton GI (2006) Vesicular glutamate transporter expression in supraoptic neurones suggests a glutamatergic phenotype. J Neuroendocrinol 18:253-265.

Quignard JF, Mironneau J, Carricaburu V, Fournier B, Babich A, Nurnberg B, Mironneau C, Macrez N (2001) Phosphoinositide 3-kinase gamma mediates angiotensin II-induced stimulation of L-type calcium channels in vascular myocytes. J Biol Chem 276:32545-32551.

Sahu A (2003) Leptin signaling in the hypothalamus: emphasis on energy homeostasis and leptin resistance. Front Neuroendocrinol 24:225-253.

Smithson KG, Hatton GI (1990) Immunocytochemical identification of electrophysiologically characterized cells in brain slices. In: Handbook of chemical neuroanatomy (Hokfelt T, ed), pp 305-350. Amsterdam: Elsevier.

Stern JE, Armstrong WE (1997) Sustained outward rectification of oxytocinergic neurones in the rat supraoptic nucleus: ionic dependence and pharmacology. J Physiol (Lond) 500:497-508.

Su H, Alroy G, Kirson ED, Yaari Y (2001) Extracellular calcium modulates persistent sodium current-dependent burst-firing in hippocampal pyramidal neurons. J Neurosci 21:4173-4182.

Suter KJ, Wuarin J-P, Smith BN, Dudek FE, Moenter SM (2000) Whole-cell recordings from preoptic/hypothalamic slices reveal burst firing in gonadotropin-releasing hormone neurons identified with green fluorescent protein in transgenic mice. Endocrinology 141:3731-3736.
Tsunoda Y, Owyang C (1994) A newly cloned phospholipase A2-activating protein elicits $\mathrm{Ca} 2+$ oscillations and pancreatic amylase secretion via mediation of $\mathrm{G}$ protein beta/phospholipase A2/arachidonic acid cascades. Biochem Biophys Res Commun 203:1716-1724.

Viard P, Exner T, Maier U, Mironneau J, Nurnberg B, Macrez N (1999) Gbetagamma dimers stimulate vascular L-type Ca2+ channels via phosphoinositide 3-kinase. FASEB J 13:685-694.

Vogt S, Grosse R, Schultz G, Offermanns S (2003) Receptor-dependent RhoA activation in G12/G13-deficient cells: genetic evidence for an involvement of Gq/G11. J Biol Chem 278:28743-28749.

Wakerley JB, Lincoln DW (1973) The milk-ejection reflex of the rat: a 20- to 40 -fold acceleration in the firing of paraventricular neurones during oxytocin release. J Endocrinol 57:477-493.

Wakerley JB, Clarke G, Summerlee AJ (1994) Milk ejection and its control. In: The physiology of reproduction (Knobil E, Neill JD, eds), pp 11311177. New York: Raven.

Wang YF, Hatton GI (2004) Milk ejection burst-like electrical activity evoked in supraoptic oxytocin neurons in slices from lactating rats. J Neurophysiol 91:2312-2321.

Wang YF, Hatton GI (2005) Burst firing of oxytocin neurons in male rat hypothalamic slices. Brain Res 1032:36-43.

Wang YF, Hatton GI (2006) Mechanisms underlying oxytocin-induced excitation of supraoptic neurons: prostaglandin mediation of actin polymerization. J Neurophysiol 95:3933-3947.

Wang YF, Negoro H, Honda K (1997) Effect of interhemispheric sections of the hypothalamus on milk-ejection bursts of supraoptic oxytocin neurones during bilateral and unilateral suckling in the rat. Neurosci Lett 227:17-20.

Wang YF, Gao XB, van den Pol AN (2001) Membrane properties underlying patterns of GABA-dependent action potentials in developing mouse hypothalamic neurons. J Neurophysiol 86:1252-1265.

Wang YF, Ponzio TA, Hatton GI (2006) Autofeedback effects of progressively rising oxytocin concentrations on supraoptic oxytocin neuronal activity in slices from lactating rats. Am J Physiol Regul Integr Comp Physiol 290:R1191-R1198.

Yevenes GE, Peoples RW, Tapia JC, Parodi J, Soto X, Olate J, Aguayo LG (2003) Modulation of glycine-activated ion channel function by G-protein betagamma subunits. Nat Neurosci 6:819-824.

Zhong M, Yang M, Sanborn BM (2003) Extracellular signal-regulated kinase $1 / 2$ activation by myometrial oxytocin receptor involves Galpha(q)Gbetagamma and epidermal growth factor receptor tyrosine kinase activation. Endocrinology 144:2947-2956. 